\title{
ÉTICA Y ESTÉTICA EN TRES RELATOS INFANTILES PERUANOS
}

\author{
Rosa Carrasco Ligarda* \\ Universidad Femenina del Sagrado Corazón \\ rocarrascoligarda@yahoo.com.ar
}

Resumen: El artículo presenta un análisis de los valores en tres relatos peruanos: «El bagrecico» de Francisco Izquierdo Ríos (Saposoa, San Martín), los libros Los días de Carbón de Rosa Cerna Guardia (Áncash) y El volador invencible de Jorge Eslava (Lima). Las historias de vida de los protagonistas de esos textos los presenta como personajes redondos, por ende se conoce su actuación y su mundo interior a través de diversas facetas. Ese cúmulo de experiencias aproxima al impacto que produce en ellos las circunstancias que les toca vivir y a sus respuestas que van enriqueciendo su relación con el mundo y su personalidad. Desde esa perspectiva, al ser relatos de aprendizaje, los personajes que se van haciendo en el día a día.

* Rosa Carrasco Ligarda es doctora en Filología por la Universidad Complutense de Madrid. Ha estudiado tres maestrías y seguido diversos cursos de actualización. Ejerció la docencia a nivel de pre y posgrado en diversas universidades. Ha escrito numerosos artículos sobre temas de literatura y lingüística, y libros que están en edición; ha presentado numerosos libros, ponencias y conferencias. Actualmente, es directora de la revista institucional Consensus de la UNIFÉ. Además es Directora del Centro de Investigación de la Universidad Femenina del Sagrado Corazón, docente en la Facultad Teología Pontificia y Civil de Lima y es vicedirectora técnica del equipo de DiPerú que prepara el primer diccionario de peruanismos de la Academia Peruana de la Lengua. 
El mundo configurado en los tres textos permite, con un enfoque analítico y comparativo, comentar la relevancia de algunas de las experiencias de los protagonistas y el sentido de su quehacer desde una perspectiva ética, por el valor que cobra el acto dentro de una existencia cotidiana que tiene como eje principios que guían el obrar. Esto permite realizar un paralelo con las circunstancias que forman parte de la existencia humana, dado que los relatos literarios son metáforas de la existencia y presentan, como espejos, rostros en los cuales el ser humano se reconoce.

Palabras clave: bagrecico, personalidad, perspectiva ética, experiencia, existencia.

\section{ETHICS AND ESTHETICS IN THREE PERUVIAN INFANT STORIES}

ABSTRACT: The article presents an analysis of values in three Peruvians stories: «El bagrecico» by Francisco Izquierdo Rios (from Saposoa, San Martin department), Los días de Carbón by Rosa Cerna Guardia (from Ancash) and El Volador invencible by Jorge Eslava (from Lima). The life stories of these texts main characters are presented as round ones, and their performance and inner worlds are known through various facets. The amount of experience approximates to the impact it has on the characters the circumstances in which they live and the answers are enriching their relationship between the world and their personalities. From this perspective, since they are learning stories, the characters are made on day to day.

The world depicted in the three texts allows an analytical and comparative approach for discussion of the relevance of some of the characters, experiences and the meaning of their work from an ethical 
perspective. The amount charged by the act within a daily life whose key principles guide the actions enable a parallel with circumstances that are part of human existence since literary stories are metaphors for the existence and reflect, in the same way as mirrors, faces in which the human being identifies himself.

KEYWORDs: bagrecico, personality, ethical perspective, experience, existence.

\section{INTRODUCCIÓN}

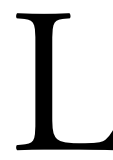

a primera intención del presente trabajo fue abordar el análisis de los valores en los relatos infantiles tradicionales en el Perú; sin embargo, los personajes míticos presentes en ellos son inestables. Estos presentan caracterizaciones particulares dado que responden a una cosmovisión propia de pueblos nativos o a creencias acuñadas con múltiples variantes en las cuales un personaje como el muqui, duende de las minas, puede alertar de los peligros, pero también conducir a la muerte o vengarse. Numerosos relatos coinciden en que se lo puede atrapar para hacer pactos sobre cómo enriquecerse, realice las actividades de un trabajador a cambio de alcohol, coca o una mujer, pero si se incumple, el muqui se venga quitando la vida. Otro mito solar de origen prehispánico es el del arco iris que representa fuerzas oscuras que dañan al ser humano. El arco iris en la época incaica era una deidad relacionada con el Sol, astro del cual los incas, máximos gobernantes del imperio incaico, se consideraban hijos. Como entendían la existencia de una afinidad entre el Sol y el arco iris, tomaron sus colores para representar su imperio. El mito del arco iris lo recogió el Inca Garcilaso de la Vega en Los comentarios reales, cuya primera parte fue publicada en 1609. Actualmente, forma parte de las creencias populares 
en el Perú y en el Ecuador, y se mantiene la creencia de que daña: no se lo puede mirar porque pudre los dientes, tampoco se lo puede señalar porque destroza el dedo que lo apunta.

La presente exposición se centra, entonces, en el tratamiento de los valores a partir de tres relatos: «El bagrecico» de Francisco Izquierdo Ríos, autor nacido en Saposoa, región amazónica peruana; el libro Los días de Carbón de Rosa Cerna Guardia (autora de Áncash, departamento de la sierra peruana) y el libro El volador invencible de Jorge Eslava (nacido en Lima, capital del Perú). A través de esos tres textos están representadas las tres regiones geográficas del Perú: selva, sierra y costa. Los relatos tienen vasos comunicantes con esos contextos y reflejan, en parte, su visión, del mundo.

\section{SOBRE EL VIAJE EN «EL BAGRECICO»}

«El bagrecico» presenta una trama sencilla. Un bagre pequeño, que - es un pez propio de la Amazonía, ve con admiración a un bagre anciano que ha retornado de un viaje, por lo cual lo denominan «viejo filósofo», puesto que en él se conjugan la sabiduría y la experiencia acumuladas en su existencia. Él rompe barreras y los límites convencionales de lo consensuado y tradicional, de la experiencia de vida intracultural, para remontarse a un mundo de nuevas posibilidades con la decisión de conocer el mar, que simboliza el avance del conocimiento como posibilidad ilimitada. Pero se trata de un camino en el cual cada uno solo llega hasta determinado punto.

La trama de «El bagrecico» tiene analogía con Juan Salvador Gaviota de Richard Bach, puesto que los personajes escapan del stablishment, con la diferencia de que en esta obra el protagonista es incomprendido y repudiado por su sociedad; en cambio en «El bagrecico» el bagre anciano, 
que ha realizado la proeza de llegar al mar, despierta admiración y deseo de emulación en los más jóvenes. Esas dos posturas, de aceptación o rechazo, son reflejo de las oscilaciones de la posición del medio frente a lo nuevo y al cambio, además, de los presupuestos conceptuales que animan a una sociedad. A ellos se refiere José de Ingenieros cuando habla del clima del genio, en su obra El hombre mediocre, donde señala que la genialidad requiere ciertas condiciones del tiempo y lugar para manifestarse en todo su potencial, dado que el secreto de la gloria es llegar a la hora oportuna.

El viaje en «El bagrecico» tiene sentido iniciático. Es la metáfora de la vida que se abre como posibilidad de búsqueda de concreción de metas. También es ruptura que tiene repercusiones generales en la afirmación de la individualidad y de la propia identidad de cualquiera que inicia esa ruta. Desde una perspectiva diacrónica, en el viaje hay un desarrollo y afianzamiento de las propias potencialidades y un proceso de formación, por lo cual se puede catalogar ese relato dentro de los de aprendizaje, como Cholito en los Andes mágicos de Óscar Colchado o Un mundo para Julius de Alfredo Bryce Echenique. De otro lado, el viaje, a nivel individual, implica el ejercicio del libre albedrío que rige el acto y determina respuestas con autonomía y libertad, aunque las voces de los demás acompañen, como las que tiene presentes el bagrecico: “Este es el río de las mil vueltas que me indicó el abuelo", recordó» (Izquierdo 1956: s. n.).

El bagrecico debe gobernar sus propias inclinaciones, superar los impedimentos, las limitaciones propias y los peligros del entorno. Por ejemplo, enfrentar el riesgo de ser pescado, desviarse o morir en el recorrido. Pero las dificultades son superadas, triunfa y finalmente tiene la experiencia del mar: ““¡El mar!”, se dijo el bagrecito, profundamente emocionado [...]» (Izquierdo 1956: s. n.). Pero el mar es el límite, el punto de arribo y de 
retorno. Es un sueño, pero también un tope hasta donde se puede llegar, justamente porque es ilimitado, dado que es la imagen de lo inconmensurable que no pertenece a la medida y dimensiones del hombre. De ahí dimana el peligro de penetrar en un espacio desconocido que no es posible manejar: "“El mar!”Lo vio esa noche de luna llena como un transparente abismo verde» (Izquierdo 1956: s. n.). El «abismo» genera connotaciones negativas de temor, peligro y muerte incontrolable. Tiene analogía con la metáfora marina, tópico de antiguo cuño, aplicado con profusión en el Siglo de Oro, en el cual la existencia surca un mar proceloso con el peligro de sucumbir.

Como el trayecto del viaje se cubre en un tiempo, el bagrecico siente que «Además, había crecido, su pecho era recio, sus barbas más largas, su color blanco oscuro con reflejos metálicos, no podía ser de otro modo, ya que muchos soles y muchas lunas alumbraron desde que salió de su riachuelito natal» (Izquierdo 1956: s. n.). La evolución propia y el desarrollo personal son condiciones intrínsecas del camino, de ese tiempo que hace preciosos los instantes. A decir de Borges, en el relato «El inmortal», la muerte da sentido a la vida al hacer invalorable la sucesión de momentos que la forman, como en «El bagrecico». Lo contrario, el tiempo que no supone continuidad, concebido con las mismas características, es una existencia en la que todo pierde sentido, una eternidad en la que se borran los límites del presente, pasado y futuro.

El retorno a los orígenes es también un tópico de larga data en la literatura. En «El bagrecico», además del deseo de volver a las raíces, hay la certeza del valor adquirido. El protagonista sabe que se configura como un héroe, dado que esa es la imagen socialmente acuñada y ese es uno de sus estímulos, a pesar de las dificultades: «El retorno a su riachuelito natal fue difícil. Se encontraba tan lejos. Ahora tenía que surcar los ríos, lo cual 
exige mayor esfuerzo. Con su heroica voluntad dominaba el desaliento» (Izquierdo 1956: s. n.). Va contra corriente, como la vida que no discurre necesariamente con uno, más aún cuando se han afianzado posiciones por la experiencia. Ya no se es joven y permeable a los cambios, hay un conocimiento del recorrido de la vida que nos va tornando más sabios y más maduros.

El viaje también revela la fugacidad de una existencia en la que somos y no somos los mismos, como menciona Heráclito, lo cual se relaciona con el tema de la identidad. Además, obra el olvido del impacto del tiempo porque los jóvenes se conciben eternos, como decía Carlos Bousoño, aunque el tiempo va haciendo lo suyo sin cesar. Este es un tópico en la Odisea, cuando Ulises regresa a Ítaca donde nadie lo reconoce, pero lleva el impacto de las experiencias que lo han marcado. De la misma manera, cuando el bagrecico retorna a sus orígenes, descubre que ha transcurrido un ciclo de vida dado que ya no encuentra a su madre. Su desarrollo personal implica independizarse para seguir un camino propio y pasar a ocupar el escenario que los demás van dejando, por ende, potencia el propio progreso.

Para el bagrecico el entorno ha cambiado puesto que tampoco están aquellos que conocía: «Se dio cuenta, entonces, de que era anciano. En el fondo de la pozuela, con su voz ronca, solía decir, contoneándose orgullosamente: 'Yo conozco el mar. Cuando joven he viajado a él y he vuelto'” (Izquierdo 1956: s. n.). Ese viaje circular representa una vida orientada a concretar un sueño, porque como dice el protagonista homónimo de $E l$ principito «lo esencial es invisible a los ojos» (Saint-Exupéry 2000: 88). De manera semejante, Konstantino Kavafis en su poema «Ítaca» se refiere a lo que significa el viaje como metáfora de la lucha por alcanzar metas, donde lo importante no es el arribo sino el proceso, el cómo se lo desarrolla «Ten 
siempre a Ítaca en tu pensamiento / tu llegada allí es tu destino. Más no apresures nunca el viaje. Mejor que dure muchos años / y atracar, viejo ya, en la isla, enriquecido de cuanto ganaste en el camino / sin aguardar a que Ítaca te enriquezca» (Kavafis s. f.; s. n.). De tal modo, Ítaca es el fin de un viaje de circunnavegación que ha impregnado de sabiduría y experiencias, una vida forjada como el acero que ha alcanzado la victoria con coraje y perseverancia.

Desde el punto de vista lingüístico, hay un vocabulario propio de la amazonía relacionado con el agua, con regionalismos o peruanismos. Algunos términos aparecen en el Diccionario de la Real Academia Española de la Lengua, en el caso de los peces, además del bagre, como son el bochico y el sábalo. No así expresiones como Mijanada, que es una migración de peces en gigantescos cardúmenes que avanzan por el río en ciertas temporadas, a tal extremo que casi se empujan por la inmensa cantidad. Además, hay malos pasos, que son los lugares en los ríos con aguas turbulentas y donde la navegación es peligrosa, sobre todo en la selva alta, región llena de vegetación en la vertiente oriental de los Andes peruanos.

\section{PROCESOS DE DESCUBRIMIENTO EN LOS DÍAS DE CARBÓN}

Los días de Carbón de Rosa Cerna Guardia es un relato con un narrador interno. Esto se debe a que la historia discurre a partir de la perspectiva de Maruja, una niña que cuenta sus vivencias. Haciendo una comparación breve, vemos que así como Ximena, la niña protagonista de la novela Ximena de dos caminos de Laura Riesco, ella va descubriendo un mundo particular en un campamento minero en la serranía del Perú.

De acuerdo a la macroestructura, Los días de Carbón está conformado por una introducción y setenta y un fragmentos en los cuales se narra, con 
lenguaje poético un lapso de vida de Maruja con su perrito Carbón regalo de su padre: «Me lo echó a los pies como si tirara un copo de lana negra, tibia y esponjosa [...] Apenas cabía en la palma de mis manos» (Cerna 2005: 12). Carbón recibe ese nombre por su color negro, y comparte el día a día con la protagonista hasta su muerte por salvar a dos niños de las cornadas de un toro. Ese episodio que cierra la vida de Carbón, nos aproxima al dolor y a la aceptación de la inexorable condición fugaz de la existencia. También es el descubrimiento de la trascendencia del esfuerzo sumo en actos catalogados como extraordinarios, incluso como donación de vida en aras de cristalizar un valor superior.

No obstante, más allá de la muerte, el heroísmo de Carbón es imagen modélica, enseña a vivir y ayuda a enfrentar el dolor. De ahí el sentido de las palabras de la maestra de Maruja «iNo se llora por un héroe, y si se llora, se llora de felicidad, de alegría» (Cerna 2005: 100). Aquí el procesamiento racional posibilita no solo paliar el sufrimiento, también fortalece para poder seguir adelante. De ahí la relación con un mito occidental: el ave fénix que muere y renace de sus cenizas, dado que el dolor quema y destroza. Por ende, superarlo es un re-nacimiento, simboliza una victoria. Implica sacar fuerzas de la flaqueza ante el impacto y la violencia de lo adverso e irreversible, como dice Maruja «Bendiciendo la mano de Dios que nos protegió aquella tarde, cierro esta página de los días de Carbón entre nosotros» (Cerna 2005: 101). Si toda experiencia marca y nadie es el mismo a medida que la experimenta, importa la manera de procesar, enfrentar para seguir adelante, y poder elevarse como el ave fénix con fe y fuerza renovadas sin quedarse congelado en la circunstancia.

Durante el lapso que Carbón comparte la vida con Maruja, se convierte en confidente, amigo fiel y cómplice de aventuras, aunque él no 
responda por su condición animal, dado que es un relato de corte realista. Sin embargo, el mundo Carbón está relacionado estrechamente con el humano y se lo humaniza. Incluso se le atribuye una capacidad racional de decodificación lingüística, como afirma Justino, un campesino que trabaja en la casa de Maruja «Es perrito chico, niños. Entiende todo, solo le falta hablar» (Cerna 2005: 15). Pero los animales forman parte del mundo más puro que el humano, porque siguen las leyes de su naturaleza. En cambio el hombre racionaliza en base a su cosmovisión y decide su actuación. De ahí la diferencia entre el silencio de Carbón, que se ahorma a los humanos, con Maruja que le habla y decide. Desde esa perspectiva, es significativo el contraste con los animales protagonistas de las fábulas donde asumen papeles y dialogan, pero se trata de un recurso para mostrar los repliegues de la condición humana, sin lesionar la sensibilidad, dado que los sentimos como pertenecientes a una esfera inferior y como tales, no importa qué papel encarnen, sobre todo aquellos que son vergonzosos o son acusaciones a la humanidad.

Las palabras liminares de Maruja, en Los días de Carbón, nos aproximan a ella y su mundo: «Vivo en el campo. Voy a cumplir diez años. Tengo un hermano chico, Pedro» (Cerna 2005:10). Aquí las oraciones sintéticas reflejan la expresión propia de los niños. Pero es más, desde un punto de vista lingüístico, las palabras de Maruja en Los días de Carbón también son parte de su universo sociocultural y están impregnadas del referente cultural de su comunidad, del cual es imposible separarlas. En consecuencia, el lenguaje del relato muestra a la protagonista, pero también introduce la cosmovisión de su mundo. De la misma manera que otros relatos, como Las mil y una noches, que nos introduce en la imaginación oriental. o los cuentos de los hermanos Grimm en la mitología popular 
alemana. Y es que, sincrónicamente, el lenguaje revela saberes del mundo de una sociedad, pero diacrónicamente es anterior a ella y transmite contenidos acuñados durante siglos.

Al ser un texto autobiográfico, Maruja alude a su sapiencia y a sus experiencias lúdicas: "Conozco todos los colores del arco iris y me gusta caminar descalza bajo la lluvia; recibir en la falda extendida el granizo y seguir de cerca a la perdiz hasta su nido para mirar sus huevos lustrosos y violetas» (Cerna 2005: 10). Hasta aquí, una primera caracterización de la protagonista perfila su conexión con un entorno rural, donde todo integra al hombre con la naturaleza en todas sus dimensiones: tierra, aire, fuego, agua, animales y plantas. Cabría mencionar que esta relación se percibe anteriormente en cuentos como "Los escoleros» o "Agua», de José María Arguedas, con la diferencia esencial de que en estos la infancia está signada de violencia.

Si Maruja alude a un disfrute pleno y vital en diversiones autodescubiertas, como caminar descalza o recibir el granizo en su falda, pasear por el campo descubriendo las plantas y animales, hacer collares de flores, entre muchas otras que ponen en juego la imaginación con los recursos del medio, es porque la naturaleza es mostrada como un libro que le habla y revela sus misterios, sin necesidad de sustitutos tecnológicos que generalmente adormecen la imaginación y la creatividad. Esto último ha sido demostrado por los estudios comparativos entre el rango imaginativo de los niños urbanos y rurales, dado que la tecnología aplicada en juguetes coloridos estandarizados no deja mucho espacio para la imaginación y no generan desafíos creativos.

Por otro lado, las palabras de Maruja nos aproximan a la curiosidad propia del niño en su proceso de descubrimiento y apropiación del mundo, 
como sucede en la observación de las perdices, las plantas, etc. Además, menciona su edad con la espontaneidad propia del mundo infantil, lejos aún de las vacilaciones que aparecen cuando el peso de los años se acumulan. Esto trae a relación el tópico del cuerpo, mostrado a través del niño que quiere crecer y anhela el desarrollo de su corporiedad y que, lamentablemente, se trabaja muy poco, tal vez por presupuestos religiosos.

Maruja también se refiere a su espacio, es decir su el del hogar: «Mi casa tiene tejado rojo y las paredes blanca, rodeada de sol, pencas y retamas, de sauces, eucaliptos y quinuales durante el día, y de oscuridad y paca-pacas en la noche» (Cerna 2005: 10). Aquí el espacio de la familia significa la presencia, el encuentro y la expresión de sentimientos y diálogo, así como cobijo y protección, además de esto, un avanzar individualmente y, a la vez, de manera conjunta. Asimismo, es signo de lo personal y de la intimidad. Por ende, la casa es un eje que concentra e irradia a la familia hacia el mundo y la re-une.

La historia en Los días de Carbón aproxima la vida cotidiana de una familia, en un ámbito campesino, a los acontecimientos diarios que estrechan los lazos e influyen en una convivencia armónica y sencilla dentro del hogar, con las relaciones que se establecen entre las personas del entorno, dado que el niño aprende a diferenciarse, a diferenciar a los demás y a afirmar su individualidad a través de la interacción cotidiana. Es el mundo de los padres de Maruja; de Pedro, su hermanito; de los amigos, de niños de la escuela, de los campesinos y de los hijos de los campesinos.

De entre los muchos personajes, Maruja se refiere a Marcos, un niño muy pobre que tiene cinco años y no va a la escuela, evidencia del presente analfabetismo rural. la protagonista nos relata acerca de él: «Tiene tres profesiones a la vez: en la mañana, al alba, es vendedor de leche y de 
alfalfa. Va al pueblo en su burro. En las tardes es pastor de sus vacas. En las noches es molinero, ayuda a su padre» (Cerna 2005: 53), acude al catecismo los sábados. Además, sabe bailar huaynos con especial gracia, y cuando se le pide que lo haga «El cholito se descalza los llanques, pone una mano atrás, la otra muy alto con un pañuelo blanco, y saca el polvo del suelo como si levantara en vuelo a todos los difuntos» (Cerna 2005: 53). Otro niño del catecismo es Pedro Jacinto Pascual Ripac, el Zorzalito: «Es un chico cantor como pocos, de linda voz, pero es engreído y se hace el interesante cuando ve que preferimos al Molinerito por su sencillez» (Cerna 2005: 64). También están Faustino y Diego, dos niños danzantes que llevan cascabeles amarrados al tobillo cuando bailan, pero aún están pequeños para bailar delante de la "Patroncita», la Virgen del Pilar, aunque ellos se consuelan diciendo «-No importa que no bailemos este año, pero podemos bailar a la Virgencita, aunque nadie sino ella nos vea» (Cerna 2005: 77). El baile, en el mundo occidental, es una expresión de la integración social y de libertad, incluso de lo vedado. En el mundo andino, se integra con las creencias, entra en relación con las fuerzas de la naturaleza, se baila para la Virgen, para los santos, para los apus. Es expresión de una alegría íntima. El baile y la música son una manifestación espontánea y típica en el mundo campesino. Por otro lado se integra con el panteísmo, relación que vemos también en el relato La agonía del Rasu Niti de Arguedas, donde al bailar el dánsac recibe la presencia del espíritu de la montaña.

Entre sus múltiples exploraciones de la realidad, Maruja va al molino, lugar prohibido por su madre, para ver si se encuentra con el ichic ollco, duende artero de cabello rojizo o rubio que es hijo del supay (que en quechua significa demonio). Habita en los puquiales y debajo de la rueda de los molinos. De acuerdo a las versiones orales del mito, si un viajero 
lo carga hace que se pierda. Además, es vengativo, seduce a las mujeres, hace que los niños caigan y mueran en el agua que mueve la rueda del molino o los conduce a la muerte. Representa un peligro real en la vida que, metafóricamente, los relatos infantiles revisten con imágenes monstruosas. Tal vez el ichic ollco encarna temores ancestrales que han sentido las madres ante el peligro de que sus hijos pierdan la vida en las tomas de agua, que en su inocencia no calibren el peligro que representa la rueda de molino para su vida. De este modo se expresa el engaño al alma diáfana del niño que confía todavía y no conoce, en una dimensión plena, los vericuetos del alma humana y el peligro que pueden representar para él otras personas. Esos relatos alertan porque la infancia es candorosa, confiada y dependiente de los adultos. Como señala la escritora española de literatura infantil Ana María Matute, en los relatos para niños aparecen metáforas del mundo descarnado y terrible de los adultos.

Sin embargo, lo vedado atrae, como árbol del bien y del mal en la Biblia. Es expresión de la libertad y deseo de romper límites. Frente a esto, Maruja le dice a Carbón: «Tengo una tentación loca por conocerlo. Creo que algún día [...] ¿por qué no hoy mismo? ¡Claro! ¡Vamos Carbón! Pero, ¿y el permiso? Tienes razón, si pido permiso no podré conocerlo nunca» (Cerna 2005: 65). Aquí vemos una acción que se independiza de los modelos sociales que son reconocidos como modificadores del comportamiento. Aceptarlos y hacerlos propios o desligarse de ellos es signo de autonomía. Los modelos son esenciales para ser, dado que si no hay modelos no hay topes.

Maruja sabe que al duende gusta del canto, ella canta y espera pero el ichic ollco no aparece. De pronto, siente que alguien se aproxima y le pide a Carbón esconderse porque sabe que ha transgredido la norma, pero hay una vuelta al orden cuando llega su padre, imagen tutelar protectora, "iAhí viene 
papá, Carbón! Escondámonos aquí. Carbón, ven acá. ¿Qué haces moviendo la cola como un abanico? No se puede contigo. ¡Ven!» (Cerna 2005: 65) Carbón saluda feliz al papá de Maruja que, casualmente, ha ido al molino. El molino es un límite, peligro, profundidad y espiral que succiona y lleva a la muerte. Maruja quiere probarse, para ver si puede resistir. Aproxima al mito de Narciso que muere por verse en el agua. Pero a diferencia de ese relato, el universo mítico popular que aparece en Los días de Carbón realmente forma parte de las creencias en el Perú y se ancla con la vida.

El mundo del campo es pleno, se abre a la mirada en su amplitud. Tiene semejanza con la nobleza de Maruja que reboza de alegría porque ha llegado la primavera. Goza la naturaleza con Carbón y le dice:

Mira el azul purísimo del cielo, el sol como recién lavado [...] Y tú ¿no sientes en el alma cómo el aire se nos cuela fresco y limpio con olor a flores y sabor a miel? [...] Te sienta tu collar de arrayanes, y a mí esta flor en la cabeza. ¿No quieres correr, Carbón, en lugar de hacer el tema? [...] es la primavera que nos ha vuelto así alegres, traviesos e inquietos. Carbón, tú y yo somos la primavera en marcha. Corramos sin fin. (Cerna 2005: 74).

Esa primavera diáfana en realidad es el alma de Maruja, esto se traduce en su alegría de vivir y en las acciones solidarias con otras personas, como Juanito, el niño lisiado que ve el mundo a través de su ventana y a quien lleva flores y diálogo. Todo es signo de la primavera íntima del corazón de Maruja, de su mirada transparente y abierta al mundo. 


\section{DESARROLLO DE POTENCIALIDADES INDIVIDUALES Y COLECTIVAS EN EL VOLADOR INVENCIBLE}

El volador invencible de Jorge Eslava es un relato dividido en quince partes. Por ser de corte autobiográfico, al igual que Los días de Carbón, Joaquín, el protagonista, narra la historia. Todo empieza cuando se entera de que en el colegio hay un campeonato de fulbito y su salón de segundo de primaria debe enfrentarse con el de cuarto de primaria. A partir de ese momento, los niños entrenan en el colegio y aprenden las reglas del juego. Por su parte, el papá de Joaquín que disfruta de pichanguitas, es decir, partidos amistosos de fulbito, con sus amigos los fines de semana, se alegra con la noticia y le promete "-iVas a ver, te voy a poner a punto" (Eslava 2004: 27). Lo entrena y se emociona contándole sobre los grandes arqueros mundiales con un lenguaje cálido, moviéndose y saltando como ellos, como cuando le habla de «El principal de todos, uno que le decían El Divino: Se paró y se volvió a tirar varias veces mientras seguía contándome: // —Era español [...] del Real Madrid [...] se llamaba Ricardo Zamora [...] FUNN [...] usaba gorro [...] chompa de cuello alto [...] fue durante veinte años [...] lo máááximo» (Eslava 2004: 29). Aquí el valor de la preparación mental, el conocimiento de los paradigmas más altos que estimulen la emulación, generan alicientes sobre un recorrido ya marcado por hitos que despiertan aprecio por lo que se hace. De esa manera se pueden cambiar los prejuicios, dado que a Joaquín le parece poco estimulante estar parado en el arco. El papá de Joaquín cambia ese desánimo y despierta el optimismo con la intención de que su hijo sea un gran arquero.

Por ello, en sus entrenamientos, le enseña los secretos para 'volar' y tapar las pelotas en el arco. Aquí se demuestra la trascendencia de la motivación que despierta el interés y la voluntad en el esfuerzo de alcanzar metas, ya 
que el niño tiene deseos de aprender y se interesa, sobre todo, cuando es consciente de sus logros y avances para seguir desplegando empeño con el fin de desarrollarse más. Desde esa perspectiva, es significativo el título del libro El volador invencible, ya que, por una parte, alude a la pericia que adquiere Joaquín como arquero, pero también se refiere al impulso de elevarse para superar los impedimentos en aras de concretar objetivos. Simbólicamente, lo alto está relacionado con lo superior y con lo que despierta admiración, en contraposición con lo bajo que se relaciona con lo ruin y oscuro.

Lo importante en ese camino es el proceso de preparación individual y colectivo. Que los niños comprendan que para lograr un objetivo es necesario sistematizar un programa de actividades, dado que no basta la buena voluntad, como sucede en los primeros entrenamientos durante los recreos del colegio como, cuenta Joaquin: «apenas salíamos al recreo estábamos PUM PUM pateando la pelota por donde sea, como locos» (p. 22). Se trata de experiencias previas que, si no se canalizan, significan un desperdicio de energía y tiempo sin alcanzar logros significativos. El cambio acontece cuando el profesor de educación física les explica las reglas del juego, señala posiciones de los jugadores en la pizarra y empieza a entrenarlos. Aquí se trata del valor del conocimiento y de un objetivo claramente definido. Para alcanzar el máximo nivel, es necesario que se ame lo que se hace, se encuentre gusto, se desarrolle disciplina y constancia, como sucede en el relato "El bagrecico», dado que la energía se genera en uno mismo. Más aún, esa energía se potencia en un equipo capaz de superar las diferencias individuales a la vez que desarrolla una capacidad de respuesta conjunta, concepto también desarrollado en la fábula El granjero y sus hijos.

Además, en un trabajo en equipo es importante aprender a compartir las actividades, aunque cada uno tenga funciones particulares, 
pero en conjunto hay estrategias comunes. Esa integración lleva al triunfo al equipo de Joaquín que gana a su rival por un gol. Después deben jugar entre campeones, y les toca enfrentar a los más grandes, al equipo de sexto grado que ha goleado a los de tercero por once goles a cero. El campeonato entre segundo y sexto termina cero a cero y se define con penales. El último penal le toca a Joaquín:

Ahora era mi turno para desquitármela. Delante de la bola, miré al arquero que tapaba todo el arco. Volteé y vi a mi papi que se comía las uñas. Él me miró y me señaló la punta de su zapato. Entendí. Di un paso y metí tal puntazo que no sé por dónde entró la pelota, la cosa es que fue GOOOOLLLLLLLLLLL y todos se me tiraron encima y me hicieron papilla, pero no importaba porque habíamos ganado. (Eslava 2004: 85).

Esta escena evoca la contienda entre David y Goliat. Esta victoria que nadie la esperaba, pero se logra. Es así como El volador invencible presenta la integración entre la escuela y el hogar, el acompañamiento familiar, y la apertura y disposición de los estudiantes para realizar una actividad que desarrolla las potencialidades individuales. Además, propone la solidaridad y el gozo de ser actores y no sujetos pasivos, como normalmente sucede en los espectáculos deportivos masivos.

\section{CONCLUSIÓN}

Como se ha visto, una aproximación a los relatos infantiles permite descubrir diferentes maneras de pensar la niñez desde diversas percepciones. Entre la multiplicidad de valores que se presentan, uno que no siempre se encuentra es el humor. El volador invencible es un relato con una expresión dialógica 
que se desarrolla en un ambiente urbano, a diferencia de «El bagrecico» $\mathrm{o}$ Los días de Carbón, pero en todos se presentan las actividades que forman parte de la vida que se enriquece en las relaciones con los seres con los cuales se la comparte, buscando cristalizar las utopías que alientan el camino de la vida. Es así como los tres textos que hemos tratado ayudan a vivir y a encontrar la felicidad en las actividades cotidianas que conforman a nuestra vida. He aquí el principal trasfondo ético que ha quedado evidente en estos comentarios acerca de las diversas prácticas y estéticas, correspondientes a tres textos emblemáticos de literatura peruana contemporánea. 


\section{BIBLIOGRAFÍA}

Arguedas, José María 1983

«Relatos». Obras completas. Lima: Editorial Horizonte.

BLANCO, Lidia 2007

Leer con placer en la primera infancia: abrir un libro... abrir el mundo. Buenos Aires: Noveduc.

Bryce, Alfredo

1983

Un mundo para Julius. Lima: Mosca Azul Editores S.R.L. Francisco Campodónico Editores.

Cerna Guardia, Rosa

Los días de Carbón. Lima: Santillana.

Cerrillo, Pedro C. y César Sánchez Ortiz 2010

Tradición y modernidad de la literatura oral: homenaje a Ana Pelegrin. Cuenca: Universidad de Castilla-La Mancha.

Colchado Lucio, Óscar 2005

Cholito tras las huellas de Lucero. Lima: Santillana. 
De la Vega, Garcilaso

1959 [1609]

Comentarios reales de los incas. Lima: Departamento de Publicaciones de Universidad Mayor San Marcos.

DíAz Ronner, María Adelia 2001 Cara y cruz de la literatura infantil. Buenos Aires: Lugar.

DURAn, Teresa

2009

Albumes y otras lecturas: análisis de los libros infantiles. Barcelona: Octaedro

EsCOBAR, Alberto

1960

La narración en el Perú. Lima: Editorial Juan Mejía Baca.

EsLAVA, Jorge

2004

El volador invencible. Lima: Alfaguara.

Flores de Naveda, Carlota

1984

Reflexiones y critica en torno a la literatura infantil. Lima: Janos.

Henche Zabala, Irene 2008

Educar en valores a través de los cuentos. Buenos Aires, Bonum. 
ROSA CARRASCO LIGARDA

INGENIEROS, José

1988

El hombre mediocre. Lima: Mantaro.

IzQUIERdo Ríos, Francisco

1956

«El bagrecico». Diario Inca. Documento disponible en <http://www.diarioinca. com/2009/08/elbagrecico-francisco-izquierdorios.html>. Consulta hecha en 26/09/2013.

KaVAFIS, Konstantino

s. e.

«Ítaca». Documento disponible en <http:// huespedes.cica.es/aliens/gittcus/kavafis $>$. Consulta hecha en 02/10/2013.

Lage Fernández, Juan José 2005 Animar a leer desde la biblioteca. Madrid: CCS.

Cómo analizamos relatos infantiles y juveniles. 2004 Bogotá: Norma.

MeIgs, Cornelia 1959

A critical history of children's literature; a survey of children's books in english from earliest times to the present. New York: The Mac-Millan Co. 


\section{ÉTICA Y ESTÉTICA EN TRES RELATOS INFANTILES PERUANOS}

NobiLe, Angelo

1999

Literatura infantil y juvenil: la infancia y sus libros en la civilización tecnológica. 2. ${ }^{\mathrm{a}}$ ed. Madrid: Morata.

PAstoriza de ETCHebarne, Dora

El cuento en la literatura infantil. Buenos Aires: Kapelusz.

Pérez Torras, Gloria y M. Carmen Shelly De Vidal 2007 Expresión y comunicación. Barcelona: Altamar.

PorTell, Joan 2007

Me gusta leer: consejos para conseguir que tu hijo se convierta en un gran lector: los libros imprescindibles. Barcelona: CEAC.

Real Academia Española 2001

Diccionario de la Real Academia Española de la Lengua. Vigésima segunda edición. Madrid: Espasa.

Rosell, Joel Franz 2001

La literatura infantil: un oficio de centauros $y$ sirenas. Buenos Aires: Lugar.

SAINT EXUPÉry, Antonie de

2000

El principito. Madrid: Alianza/Emecé. 
ROSA CARRASCO LIGARDA

SosA, Jesualdo

1963

La literatura infantil; ensayo sobre ética, estética y psicopedagogía de la literatura infantil. $4 .^{\mathrm{a}} \mathrm{ed}$. Buenos Aires: Losada.

Wischñevsky, Amalia; Alicia Zaina y Elvira Rodríguez De Pastorino 2000 ¿A qué juegan las palabras?: propuestas lúdicoliterarias. Buenos Aires: Magisterio del Río de la Plata. 